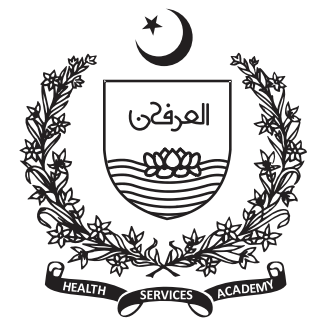

${ }^{1}$ Department of

Community Health Science,

Aga Khan University,

Karachi, Pakistan

2 TPL Life Insurance Ltd.

Karachi, Pakistan

${ }^{3}$ Aga Khan University

Institute for Educational

Development, Karachi,

Pakistan

\section{Corresponding Author:}

Anam Shahil Feroz (ASF)

Email:

anam.sahyl@gmail.com

\title{
Reducing Stigma and Discrimination around Covid-19 Outbreak
}

\author{
Anam Shahil Feroz ${ }^{1}$, Shahil Sultan², Ridah Feroz ${ }^{3}$
}

In the wake of Covid-19 pandemic, nations around the world are facing unprecedented crisis with disrupted social, economic and political lives (World Health Organization, 2020a). As of June 18, 2020, there have been 8,408,202 confirmed cases globally, with 451,462 deaths (World Health Organization, 2020b). As the pandemic continues to escalate, there is an increasing concern about stigma, and discrimination associated with Covid-19 (Center of Disease Control and Prevention, 2020). It has now become more than a health issue; it is a virus that exacerbates xenophobia, hate and exclusion among communities (Corrigan, 2020). Globally Governments have step up to respond to several health systems issues which emerged with a growing tide of pandemic, however, very little attention has been given to the issue of sigma associated with Covid-19. Past experiences have shown that pandemics tend to provoke xenophobia, stigma, and discrimination. This was the case with Ebola and MERS, and COVID-19 is no exception (American Psychological Association, 2020).

According to World Health Organization (WHO), the current COVID-19 outbreak has provoked social stigma and discriminatory behaviours against people of certain ethnic backgrounds as well as anyone perceived to have been in contact with the virus (UNICEF, 2020). Several groups are experiencing stigma associated with Covid-19 including, people of Asian descent, people returning from travel, health care workers, people with the disease and their family and friends and people released from quarantine (Mayo Clinic, 2020). Amongst all, people who tested positive for COVID-19, have recovered from being sick with COVID-19, or were released from COVID-19 quarantine are the most obvious victims. Individuals are being disrespected and discriminated because they are tested positive for Covid-19 and it is immoral just like any forms of racism, sexism, and ageism (Corrigan, 2020).

Basically, confusion and uncertainty create a fertile breeding ground for stereotypes, bias, and discrimination. Humans as emotional beings have a well-established need to know the "why" of an occurrence, particularly uncommon and alarming happenstance (Corrigan, 2020). Why is the Covid-19 pandemic afflicting the world? It is important to understand that the stigma occurs when distance from the virus is confused with distance from the tainted person; when we shift the question from what is to blame to who is to blame (Corrigan, 2020). According to $\mathrm{WHO}$, there are three main factors responsible for fueling stigma and discrimination amid Covid-19. These include: 1) it is a disease that's new and for which there are still many unknowns; 2) we are often afraid of the unknown; and 3) it is easy to associate that fear with 'others' (UNICEF, 2020).

Stigmatized individuals may suffer from isolation, abandonment, depression, anxiety, and public humiliation (Adja, Golinelli, Lenzi, Fantini, \& $\mathrm{Wu}, 2020)$. Experiences from previous epidemics and pandemics have shown that stigmatization of certain groups can drive people to hide their diagnosis to avoid discrimination, discourage them from seeking 
health care and prevent them from practicing healthy behaviors (UNICEF, 2020). Perhaps more concerning, stigma negatively influences the emotional, mental, and physical health of discriminated groups and the communities they live in. In the longer term, stigmatization and discrimination can undermine social inclusion and prompt possible social isolation of groups, which might contribute to a condition where the virus is more, not less, likely to spread (Corrigan, 2020).

To tackle this aspect of the crisis, health strategies should not only focus on the medical dimensions of the pandemic but also the human rights specific consequences of Covid-19 (Corrigan, 2020). WHO endorses that as we collectively work to contain the Covid-19 spread; governments, citizens, media, key influencers and communities should also step up to counter the contagion of prejudice and stigma (UNICEF, 2020). To avoid fuelling fear and stigma around Covid-19, it is important to build trust in reliable health information sources, show empathy and maintain privacy and confidentiality of those affected, avoid use of negative language that can cause stigma, give people freedom to speak out against negative behaviours and statements, and amplify the voices of people with lived experience of coronavirus (Adja et al., 2020; Mayo Clinic, 2020; UNICEF, 2020). More importantly, an enabling environment needs to be ensured in which Covid-19 and its impact can be discussed and addressed freely, ethically, and efficiently. It is significant to recognize the fact that Covid-19 is a common enemy that does not care about ethnicity or nationality, faction, or faith. "It attacks all, relentlessly." Thus, its high time that all individuals around the globe, should strengthen the immunity not only against Covid-19 but also against the 'virus of hate'(Nature, 2020).

\section{References}

1. Adja, KYC, Golinelli, D, Lenzi, J, Fantini, MP, \& Wu, E.. Pandemics and social stigma: Who's next? Italy's experience with COVID-19. Public Health. (2020)

2. American Psychological Association. (2020). Combating bias and stigma related to COVID-19. In.

3. COVID-19 (coronavirus) stigma: What it is and how to reduce it. Mayo Clinic. (2020). Retrieved from https://www.mayoclinic.org/diseasesconditions/coronavirus/in-depth/coronavirusstigma/art-20484278.

4. Corrigan, Patrick.. On the Stigma of COVID-19. Let's separate the illness from the patient. (2020) Retrieved from

https://www.psychologytoday.com/us/blog/thestigma-effect/202004/the-stigma-covid-19.

5. Stop the coronavirus stigma now. 580(7802), 165. Nature. (2020). doi:10.1038/d41586-020-01009-0

6. Rolling updates on Covid.19. World Health Organization. (2020a) https://www.who.int/emergencies/diseases/novelcoronavirus-2019/events-as-they-happen.

7. WHO Coronavirus Disease (COVID-19) Dashboard. World Health Organization. (2020b) Retrieved from https://covid19.who.int/.

8. Reducing Stigma. Center of Disease Control and Prevention. (2020) Retrieved from https://www.cdc.gov/coronavirus/2019-ncov/dailylife-coping/reducing-stigma.html.

9. Social Stigma associated with COVID-19. A guide to preventing and addressing social stigma. UNICEF, WHO, IFRC (2020) https://www.epiwin. com/sites/epiwin/files/content/attachments/2020-0224/COVID19\% 20Stigma\% 20Guide\% 2024022020_1. pdf adresinden erişilmiştir. 